UDC 621.039 .586

\author{
S. I. Azarovํ, V. M. Yevlanov², A. V. Taranovskyi ${ }^{3}$ \\ ${ }^{1}$ Nuclear Research Institute, National Academy of Sciences \\ of Ukraine, Kyiv \\ 2 State Scientific and Technical Center for Nuclear \\ and Radiation Safety, Kyiv, Ukraine \\ ${ }^{3}$ ENERGORISK Ltd., Kyiv, Ukraine
}

\section{Development of in-pile Power Monitoring System Based on the Calorimetric Gamma-Detector}

In this analytical overview, domestic and foreign scientific and technical publications focusing on research of different types of in-core detectors and in-core instrumentation systems (ICIS) are considered. The issues of ICIS development are discussed and a novel nonconventional concept of reactor monitoring is suggested.

Keywords: calorimetry, in-core instrumentation systems, in-core detectors.

\section{С. І. Азаров, В. М. Євланов, О. В. Тарановський}

Розробка системи внутрішнього реакторного контролю на базі калориметричного гамма-детектора

В аналітичному огляді розглядаються вітчизняні та зарубіжні науково-технічні публікації стосовно проблеми дослідження різних типів детекторів активної зони і систем внутрішнього реакторного контролю (СВРК). Обговорюються проблеми розвитку СВРК і пропонується нетрадиційна концепція контролю роботи реактора.

Ключов і слов а: калориметр, система внутрішнього реакторного контролю, детектор активної зони.
$\mathrm{T}$ he operational effectiveness and reliability of nuclear reactors depend to a great extent on their thermal stresses. Therefore, the issues of justified and reliable monitoring of power generation are of utmost significance. We refer to instrumentation providing in-core power distribution monitoring within the In-Core Instrumentation System (ICIS). We distinguish ICIS detectors, communication equipment, and distributed information management with software.

The aim of this paper is to summarize and classify data on methods and means of in-core reactor monitoring for the world's Nuclear Power Plants (NPPs) and suggest a brief outline of a new type of in-core calorimeter detectors.

The following classification of methods and means for in-core energy release monitoring is suggested (Fig. 1):

- monitoring regarding physical fields (thermal, neutron and gamma);

- shaping of physical fields (activation, ionization, emission charge, calorimeter);

- technical modes of implemented instrumentation: Ionization Chambers (IC), Self-Powered Neutron Detectors (SPND), Activation Detectors (AD), Fission Chambers (FC), Neutron Thermopiles (NT), Gamma Cameras (GC), Gamma Thermometers (GT), Calorimetric Detectors (CD);

- measurement of time and spatial in-core energy release characteristics: distribution, point distribution, quasidistribution, occasional and permanent actions, stationary mounted and relocated means, detector units and combined trains.

Under an activation detector we mean a transducer capable of detecting ionization radiation in the sensitive element with induced radioactivity under radiation exposure. An ionization detector is a transducer whose functioning is based on the ionizing effect in the sensitive element under radiation exposure. An emission detector is a unit where potential difference between two insulated electrodes induces transfer of charged particles under radiation exposure.

A calorimetric detector highlights heat energy distribution in the sensitive element following energy transfer. Under an In-core Detector Unit (IDU) we assume a primary transducer of instrumentation distributed in the reactor core leading to conversion of radiation energy into the type of energy suitable for on-line generation of signals and their transfer to secondary instrumentation. Methods and means for monitoring of in-core energy release distribution are addressed regarding the above classification.

Overview of Evolution and Development of Methods and Means for Energy Release Monitoring. For flexibility of retrospective analysis, the development of methods and means for energy release monitoring in the period 1960-1992 is divided into three groups: early on-going efforts, extensive development and stabilization period in NPP engineering [1].

Early on-going efforts in NPP development encompass (1960-1968) featured pilot commercial reactor designs, power capacity from 100 to $300 \mathrm{MW}$, where design criteria and scientific and technical approaches were validated. Design, operating parameters and functional performance differed much for nuclear reactors. They had insignificant in-core dimensions and were characterized by low thermal and energy stresses. It resulted from the lack of process equipment production and little experience in reactor operation. Therefore, in this period, individual designs of ICIS were under development for each NPP, and there were numerous methods and means of in-core reactor monitoring. In the period in question, there was a range of thermal, axial power distribution, neutron and gamma activation, ionization, charge and calorimetric methods for radial 


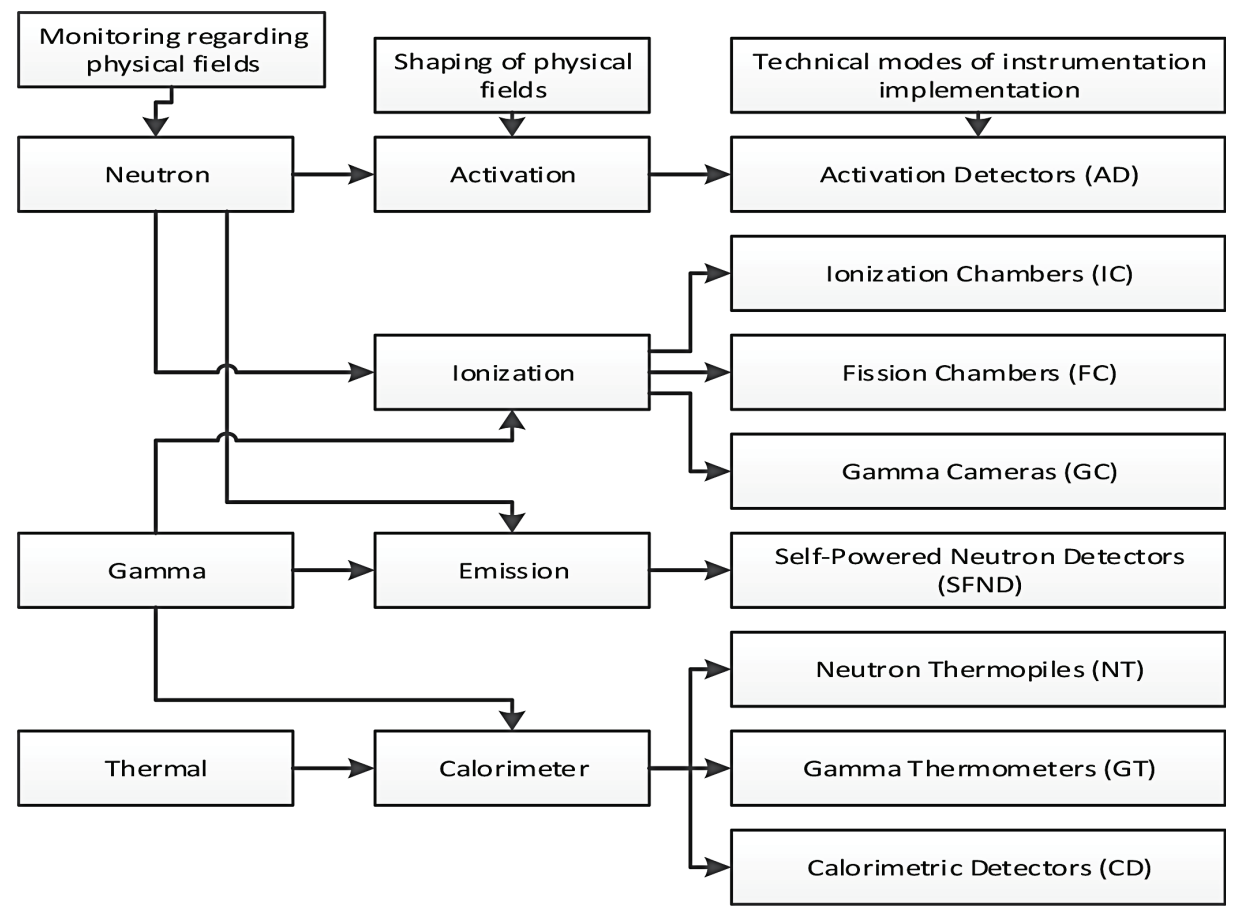

Fig. 1. Classification of in-core detectors

reactor monitoring. Activation detectors performed in distribution periodic mode with wire or ball sensing elements $\left(\mathrm{Mn}^{55}\right.$, $\mathrm{Cu}^{63}$ and $\left.\mathrm{W}^{186}\right)[2]$.

PWR, BWR and WWER reactor types employed stationary mounted instrumentation racks comprising FC, SPND and NT [3-5]. PHWR reactors used GT [6] sensor units and PWR SPND [7]. Information from in-core detector units was submitted to the instrumentation and control system usually comprising a second-generation computer. The instrumentation systems ensured reception, normalization and generalization of signals, computation of energy release distribution, detection of loss-of-coolant conditions, etc.

The stage of intensive NPP engineering development (19681976) was characterized by commercial reactors of middle power capacity (400-900 MW) with modified technical and economic parameters. NPP operating experience at this stage clearly demonstrated that performances and physical and technical characteristics were not utilized in full extent in the reactors, and physical profiling and process modifications were needed to produce significantly higher energy in the same core volume.

On the other hand, higher nuclear reactor performance parameters compared to increase in the core dimensions resulted in better thermal, technical and subsequently economic characteristics of NPP operation. For the period in question, the core volume increased on average by two times, energy stress increased by 1.5 times and lose-of-coolant factor decreased by 1.3 times.

Hence, this contributed much to monitoring of energy spatial instability distribution and sharp deviations of in-core temperature and thermal stresses, following credit of failures in in-core reactor instrumentation. In this period, the neutron method was widely used for reliable energy emission monitoring. Since already tested in-core detector units did not meet the growing requirements for middle-power reactor operation, it was urgently needed to develop new types of in-core detector units. The requirements for in-core performance are determined to a high extent by the construction design, production technology and reliability of SPND and FC [8,9]. Thus WWER-440 reactors in the USSR employed SPND with (Rh, V) emitters for the determination of neutron spectral characteristics, following transmission of signals to the Gindukush instrumentation system [10].

ICIS for RBMK reactors used 7 point SPND (Ag) distributed in the instrumentation channel for axial energy emission monitoring and 117 radial SPND. Signals from the detectors were transmitted to the Skala system with VNIEM computer [11]. BWR reactors utilized relocated and stationary distributed FC and PWR reactors utilized SPND [12, 13]. In this stage, sensors were performed in conjunction with third-generation computers M-60, M-6000, M-7000 (USSR), Produc-250 (WE, USA), IBM-130 (IBM, USA), Ge/PAC-4020 (GE, USA), C 90-40, TAC (CAE, EEC, France), and AEG 60-50 (Siemens, FRG), ensuring computation of nuclear-physical thermodynamics in compliance with technical and economical standards for NPPs, optimization of static and transient modes, etc.

The stabilization period (1976-1992) was distinguished by commissioning of reactors with sufficient power capacity (1000-1300 MW), where a great part of work was done considering enhancement of technical and economic indicators of reactor operation to reduce capital investments, following the tendency to increase of in-core instrumentation dimensions, performance parameters and energy stress.

A qualitatively new type of IDUs was also urgently needed since conventional ones became outdated and obsolete. Due to varieties in production technologies and options in assembly of units, IDUs differed much in primary sensitivity and pre-operational calibration. On the other hand, SPND and FC 


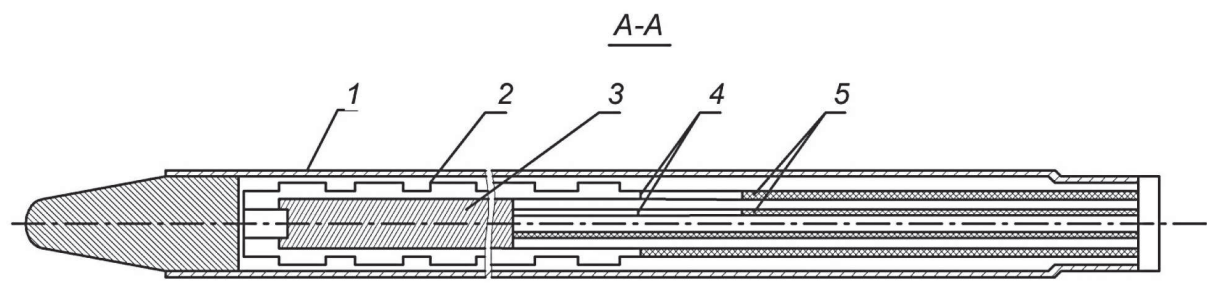

Fig. 2. Calorimetric Detector:

1 - heater element; 2 - thermal sensitivity element; 3 - gamma sensitivity body; $4-$ hot junction; 5 - mineral insulated cable

exhibited change in sensitivity under radiation exposure during operation (following $\mathrm{Rh}^{103}, \mathrm{Ag}^{109}$ and $\mathrm{U}^{235}$ burnup) and needed permanent control of detector sensitivity change [14].

That is why Ignalina NPP (RBMK-1500) used SPND with $\mathrm{GC}$ emitters as radial and axial detectors, which substantially changed the approach to ICIS development [15]. At foreign NPPs, SPND with low-burnup emitters fabricated of Pt, Er, $\mathrm{Co}$, Yo, Ta, and Cd found a wide application in ICIS [16-19]. Besides the neutron method, a considerable amount of application was given to the gamma method, where primary transducer GT was used [21].

A wide application of the gamma method for energy emission monitoring nowadays is accounted for in-core energy in NPP operation within high density of the working media where gamma radiation serves for reliable and accurate monitoring of energy emission distribution, being clearly justified among other monitoring modes [22]. For processing of output signals transmitted from IDUs, decentralized mini-computers are widely used, which are assigned to relevant functional specifications permitting the formation of expert systems.

ICIS are characterized by high requirements for performance and reliability. They should maintain energy release monitoring by dedicated channels, provide automatic self-diagnostics of system performance, and function in normal operation and emergencies. ICIS are modified and updated by means of modern microprocessor and programmable logics equipment, serving for diagnostics of anticipated operational occurrences within elements of control expert systems and human-machine interface. In the Nuclear Research Institute of the Ukrainian Academy of Sciences, considerable work has been done in the field of ICIS development based on the neutron and gamma methods of energy release monitoring, where Calorimetric Detectors $(\mathrm{CD})$ are used as in-core instrumentation (Fig. 2).

Calorimetric detectors are aimed at registration of neutron or gamma radiation in the core, experiencing high temperature, vibration and severe ionizing radiation exposure. This type of reactor instruments allows spectral selective sensitivity to varieties of ionizing radiation exposures (by various sets of gamma and neutron sensitive materials: $\mathrm{B}^{10}, \mathrm{U}^{235}, \mathrm{Th}^{232}, \mathrm{U}^{238}, \mathrm{~Np}^{237}$, $\mathrm{Pu}^{235}, \mathrm{Bi}, \mathrm{Pb}, \mathrm{Zr}, \mathrm{Fe}$, etc.) and is considered for use in systems for in-core energy release monitoring [23].

Fig. 3 shows transients for various detector types under emergency insertion of control rods, where $\mathrm{E}$ is detector signal in \% [24].

Calorimetric detectors are characterized by high reliability and relatively simple design, performance at wire insulation resistance up to $10^{3} \Omega(\mathrm{T} \leq 1000 \mathrm{~K})$ and self-calibration in operation. Comparative characteristics for neutron and gamma IDUs are summarized in Tables 1 and 2. All the above-mentioned aspects allow considering this type of in-core instrumentation to be the most promising for high-temperature reactor applications. Calorimetric gamma and neutron detectors

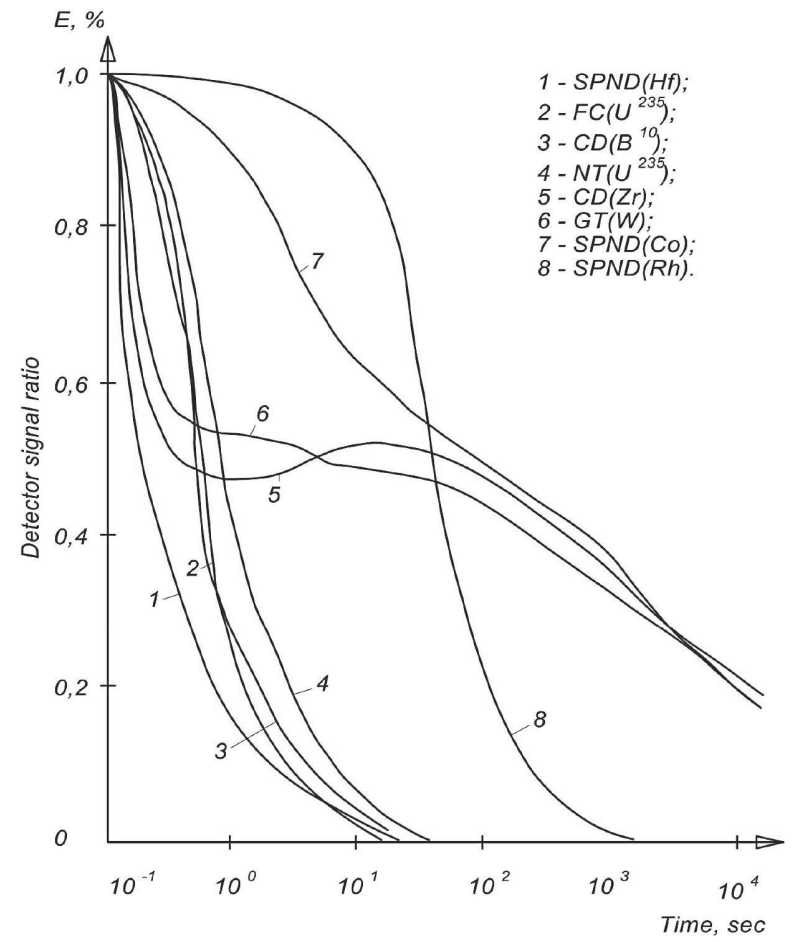

Fig. 3. In-core unit transients under insertion of control rods

were subjected to full-scale performance testing on WWER and RBMK reactors.

Gamma Method for Energy Release Monitoring. The problem of power density determination by the absorbed dose rate was investigated with use of a cylinder-like material with assigned dimensions located within the core (Fig. 4).

The following assumptions were made:

- homogeneous in-core environment;

neglect of induced $\gamma$-radiation;

- interaction of $\gamma$-radiation with the cylinder body maintained in electron equilibrium conditions.

Hence, overheating of the cylinder body in quasistationary pile mode will be determined by the following formula:

$$
q_{\gamma}\left(r_{p}, E_{\gamma}, t\right)=C_{p} \iint_{t} \sigma_{E_{\gamma}}\left(E_{\gamma}\right) \varphi_{\gamma}\left(r_{p}, E_{\gamma}, t\right) E_{\gamma} d E_{\gamma} d t
$$

where $r_{p}$ is coordinate; $E_{\gamma}$ is energy in the body; $t$ is time; $\sigma_{p}\left(E_{\gamma}\right)$ is absorbing cross-section of gamma quantum; $C_{p}$ is turnover coefficient, equal to $1.6 \cdot 10^{-13}(\mathrm{~W} \cdot \mathrm{sec} / \mathrm{MeV}) ; \sigma_{p}\left(E_{\gamma}\right)$ 
Development of in-pile power monitoring system based on the calorimetric gamma-detector

Table 1. Comparative characteristics of neutron detectors [27]

\begin{tabular}{|c|c|c|c|c|c|c|c|}
\hline Parameter & Size, & Material & Measurement range, & Sensitivity, & Maximal & Absolute & Integrated \\
\hline IDU type & $\mathbf{m m} \times \mathbf{m m}$ & element & $\mathrm{m}^{-2} \cdot \sec ^{-1}$ & $\left(\mathrm{~V} \cdot \mathrm{m}^{2} \cdot \mathrm{sec}\right)$ & temperature, $\mathrm{K}$ & error, \% & flux, $\mathbf{m}^{-2}$ \\
\hline $\mathrm{IC}$ & $25 \times 300$ & $\mathrm{BF}_{3}$ & $10^{14}-10^{18}$ & $10^{-24}$ & 523 & 4 & $10^{24}$ \\
\hline $\mathrm{FC}$ & $30 \times 76$ & $\mathrm{U}^{235}$ & $10^{12}-10^{18}$ & $10^{-22}$ & 673 & 3 & $0.2 \cdot 10^{26}$ \\
\hline \multirow{3}{*}{ SPND } & $3.0 \times 200$ & $\mathrm{Ag}$ & $10^{16}-10^{18}$ & $1.9 \cdot 10^{-23}$ & 600 & 3 & $0.5 \cdot 10^{26}$ \\
\hline & $1.8 \times 200$ & $\mathrm{Rh}$ & $10^{16}-10^{18}$ & $2.1 \cdot 10^{-23}$ & 800 & 2 & $0.8 \cdot 10^{26}$ \\
\hline & $1.5 \times 10$ & $\mathrm{Hf}$ & $10^{16}-10^{18}$ & $10^{-19}$ & 870 & 3 & $0.7 \cdot 10^{26}$ \\
\hline NT & $2.0 \times 60$ & $\mathrm{U}^{235}$ & $10^{14}-10^{16}$ & $10^{-7}$ & 900 & 5 & $0.4 \cdot 10^{25}$ \\
\hline \multirow{2}{*}{$\mathrm{CD}(\mathrm{n})$} & $4.0 \times 60$ & $\mathrm{U}^{235}$ & $10^{11-10^{18}}$ & $10^{-8}$ & 1000 & 4 & $0.6 \cdot 10^{26}$ \\
\hline & $4.0 \times 60$ & $\mathrm{~B}^{10}$ & $10^{10}-10^{16}$ & $10^{-7}$ & 600 & 4 & $0.2 \cdot 10^{25}$ \\
\hline
\end{tabular}

Table 2. Technical characteristics of gamma detectors [27]

\begin{tabular}{|c|c|c|c|c|c|c|c|}
\hline Parameter & Size, & Material & Measurement range, & Sensitivity, & Maximal & Absolute & Maximal \\
\hline IDU type & $\mathbf{m m} \times \mathbf{m m}$ & element & Gy $\cdot \sec ^{-1}$ & $(\mathrm{~V} \cdot \mathrm{sec})$ & temperature, $\mathrm{K}$ & error, \% & Gy \\
\hline GC & $6.0 \times 200$ & $\mathrm{He}$ & $0.3-1.0$ & $10-14$ & 600 & 3 & $10^{9}$ \\
\hline \multirow{2}{*}{ SPND } & $3.0 \times 600$ & $\mathrm{Pt}$ & $3.0-100$ & $5 \cdot 10^{-12}$ & 770 & 5 & $8 \cdot 10^{9}$ \\
\hline & $3.0 \times 600$ & $\mathrm{Co}$ & $1.0-100$ & $10^{-12}$ & 700 & 4 & $0.7 \cdot 10^{11}$ \\
\hline GT & $7.0 \times 100$ & $\mathrm{Fe}$ & $1.1-100$ & $10^{-4}$ & 370 & 6 & $0.3 \cdot 10^{12}$ \\
\hline \multirow{4}{*}{$\mathrm{CD}(\gamma)$} & $4.0 \times 60$ & $\mathrm{Bi}$ & $0.1-200$ & $10^{-5}$ & 500 & 3 & $10^{10}$ \\
\hline & $3.5 \times 40$ & $\mathrm{Zr}$ & $1.5-500$ & $10^{-3}$ & 900 & 5 & $10^{11}$ \\
\hline & $4,5 \times 100$ & $\mathrm{Fe}$ & $3.0-300$ & $10^{-3}$ & 600 & 5 & $0.5 \cdot 10^{12}$ \\
\hline & $4,0 \times 50$ & W & $10-400$ & $10^{-2}$ & 1000 & 7 & $0.8 \cdot 10^{12}$ \\
\hline
\end{tabular}

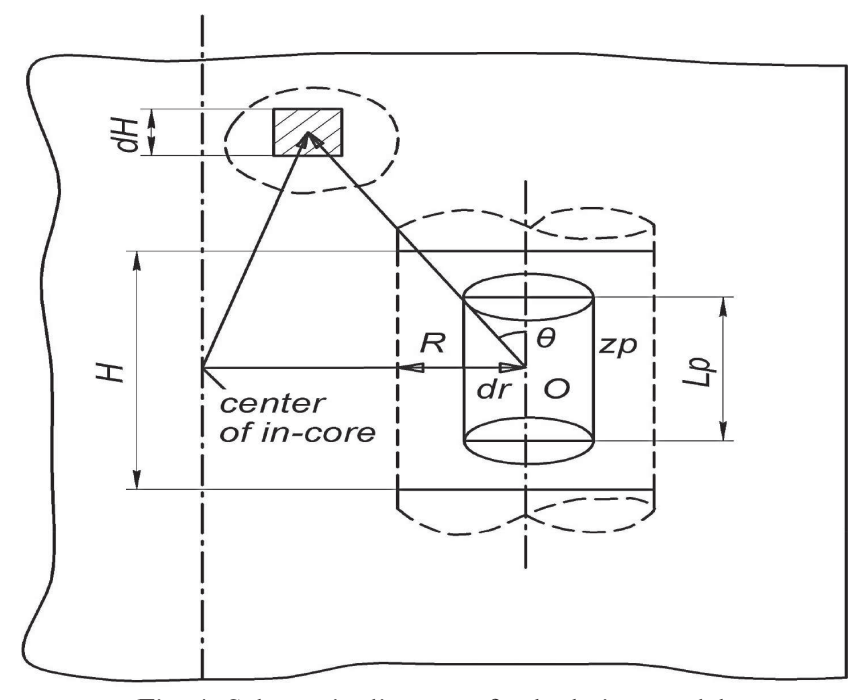

Fig. 4. Schematic diagram of calculation model: $H$ - cylinder height; $R$ - cylinder radius; $L_{p}$ - length of the sample calorimetric detector; $O-$ center of the sample calorimetric detector;

$\Theta$ - angle between the calorimetric detector and the source; $z_{p}$ - coordinate;

$\Delta H-$ change in height of the source; $\Delta r-$ change in the coordinate is absorbing cross-section of gamma quantum; $\varphi\left(r_{p}, E_{\gamma}, t\right)$ is flux density of primary $\gamma$-radiation.

$$
\sigma_{p}\left(E_{\gamma}\right)=\mu_{p}\left(E_{\gamma}\right) \rho_{p}^{-1} \cdot f\left[\mu_{p}\left(E_{\gamma}\right), \frac{4 v_{p}}{s_{p}}\right],
$$

where $\mu_{p}\left(E_{\gamma}\right)$ is absorption coefficient with $E_{\gamma} ; \rho_{p}$ is body density; $v_{p}$ is body volume; $S_{p}$ is body surface.

The flux density of primary $\gamma$-radiation is considered in core energy release as follows:

$$
\begin{gathered}
\int_{t} \varphi_{\gamma}\left(r_{p}, E_{\gamma}, t\right) d t=f\left(E_{\gamma}, L_{p}\right), \\
\mu_{\Sigma}\left(E_{\gamma}\right)^{-1}\left\{\xi_{f}\left(r_{p}, t\right) H_{\text {inst }}\left(E_{\gamma}\right)+\int_{0}^{t} \xi_{f}\left(r_{p}, \tau\right) H_{d e l}\left(E_{\gamma}, t-\tau\right) d t\right\}
\end{gathered}
$$

where $\tau$ relates to time $>10 \mathrm{sec} ; \mu_{\Sigma}\left(E_{\gamma}\right)$ is linear absorption of $\gamma$-quanta in the reactor core area; $\xi_{f}\left(r_{p}, t\right)$ is the number of fissions per unit volume of the fuel element; $H_{\text {inst }}\left(E_{\gamma}\right)$ is instant $\gamma$-radiation spectrum; $\xi_{0 f}\left(r_{p}, \tau\right)$ is the number of fissions per unit volume of the fuel element regarding time $>10 \mathrm{sec} ; H_{d e l}\left(E_{\gamma}, t-\tau\right)$ is delayed $\gamma$-radiation spectrum of fission products; 
$f\left(E_{\gamma}, L_{p}\right)$ is flux decrease function of $\gamma$-radiation in the body:

$$
f\left(E_{\gamma}, L_{p}\right)=\exp \left[-\mu_{p}\left(E_{\gamma}\right) \rho_{p} L_{p}\right] G\left[\mu_{\Sigma}\left(E_{\gamma}\right) \cdot H, \mu_{\Sigma}\left(E_{\gamma}\right) R\right]
$$

where $G$ is accumulation factor of gamma radiation:

$$
\begin{gathered}
G\left[\mu_{\Sigma}\left(E_{\gamma}\right) \cdot H, \mu_{\Sigma}\left(E_{\gamma}\right) R\right]= \\
=\int_{0}^{H} d z \int_{0}^{R} \exp \left[-\mu_{\Sigma}\left(E_{\gamma}\right) \cdot r \cdot \sec \Theta\right] \frac{r_{p} d r_{p}}{r_{p}^{2}+z^{2}},
\end{gathered}
$$

where

$$
\sec \Theta=\frac{\sqrt{\left(r_{p}^{2}+r_{0}^{2}\right)}}{z}
$$

By applying partition and considering the leak function $f\left[\mu_{p}\left(E_{\gamma}\right), \frac{4 v_{p}}{s_{p}}\right]$, dependence of $\gamma$-quantum energy rate, and formula (3) equation (1) becomes

$$
\begin{gathered}
q_{\gamma}\left(r_{p}, E_{\gamma}, t\right)=\left\{C_{p} \cdot \bar{\mu}_{p} \cdot \rho_{p} \cdot f\left(\bar{\mu}_{p}, \frac{4 v_{p}}{s_{p}}\right) \cdot \mu_{\Sigma}^{-1} \times\right. \\
\left.\times \exp \left(-\bar{\mu}_{p} \cdot s_{p} L_{p}\right) \int_{0}^{H} d z \int_{0}^{R} \exp \left(-\bar{\mu}_{\Sigma} r_{p} \sec \Theta\right) \frac{r_{p} d r_{p}}{r_{p}{ }^{2}+z^{2}}\right\} \times \\
\times\left[\int_{E_{\gamma}} \xi_{f}\left(r_{p}, t\right) H_{\text {inst }}\left(E_{\gamma}\right) E_{\gamma} d E_{\gamma}+\right. \\
\left.+\int_{E_{\gamma}} \int_{0} \xi_{f}\left(r_{p}, t\right) H_{d e l}\left(E_{\gamma}, t-\tau\right) E_{\gamma} d E_{\gamma} d \tau\right] .
\end{gathered}
$$

Define the term in curved brackets as $M_{p}$ and substitute expressions $I_{i n s t}\left(E_{\gamma}\right)$ and $I_{d e l}\left(E_{\gamma}, t-\tau\right)$ to determine the delayed $\gamma$-radiation as the overall exponent sum:

$$
\begin{gathered}
q_{\gamma}\left(r_{p}, E_{\gamma}, t\right)=M_{p}\left\{\xi_{f}\left(r_{p}, t\right) I_{\text {inst }}\left(E_{\gamma}\right) \int_{0}^{t} \xi_{f}\left(r_{p}, t-\tau\right) \times\right. \\
\left.\times \sum_{n}^{N} A(\beta)_{m} \exp \left[-\lambda(\beta)(t-\tau)_{m}\right] d \tau\right\},
\end{gathered}
$$

where $n, N, m$ is the number of considered isotopes; $A(\beta)_{m}$ is the group effectiveness of fission products; $\lambda(\beta)_{m}$ is the decay constant of fission products.

For calculation of $\xi_{f}\left(r_{p}, t\right)$ in formula (8) the Voters equation is used considering iteration Piker's method:

$$
\begin{aligned}
& \left\{\begin{array}{l}
\xi_{f}\left(r_{p}, 0\right)=q_{\gamma}\left(r_{p}, E_{\gamma}, 0\right) ; \\
\xi_{f}\left(r t_{p}, t_{1}\right)=q_{\gamma}\left(r_{p}, E_{\gamma}, t_{1}\right)-M_{p}^{-1} I_{\text {inst }}\left(E_{\gamma}\right)^{-1} \times \\
\times \int_{0}^{t} \xi_{f}\left(r_{p}, 0\right) \sum_{k=1}^{M} A(\beta)_{k} \exp \left[-\lambda(\beta)\left(t_{2}-\tau\right)\right]_{k} d \tau ; \\
\ldots \\
\xi_{f}\left(r t_{p}, t_{j}\right)=q_{\gamma}\left(r_{p}, E_{\gamma}, t_{j}\right)-M_{p}^{-1} I_{\text {inst }}\left(E_{\gamma}\right)^{-1} \times \\
\times \int_{0}^{t} \xi_{f}\left(r_{p}, t_{j}\right) \sum_{k=1}^{M} A(\beta)_{k} \exp \left[-\lambda(\beta)\left(t_{2}-\tau\right)_{k}\right]_{k} d \tau ;
\end{array}\right. \\
& j=1,2, \ldots, i ;
\end{aligned}
$$

$k, M$ is the number of considered isotopes; $i, j$ is the number of energy gaps (group).

In stationary pile mode operation, the dose rate absorbed in the cylinder body may be determined as

$$
q_{\gamma}\left(r_{p}, E_{\gamma}\right)=\int_{E_{\gamma}} M_{p}\left(E_{\gamma}\right) \xi_{f} H_{\text {inst }}\left(E_{\gamma}\right) E_{\gamma} d E_{\gamma}
$$

For this case, the problem of in-core $\gamma$-spectrum determination will be reduced to resolution of the system of integral equations.

Using recurrent relations we obtain:

$$
H_{\text {inst }}\left(E_{\gamma}\right)^{n+1}=8 \exp \left(1.1 E_{\gamma}\right) \prod_{k=1}^{k}\left[\frac{\sum_{j=1}^{J} \frac{M_{p}\left(E_{\gamma}\right)_{i, j}}{M_{p}\left(E_{\gamma}\right)_{i, j} H_{i n s t}\left(E_{\gamma}\right)_{j}^{n}}}{\sum_{j=1}^{J} \frac{M_{p}\left(E_{\gamma}\right)_{i, j}}{q_{\gamma p}\left(r_{p} E_{\gamma}\right)_{i}}}\right] \text {, }
$$

where $H_{\text {inst }}\left(E_{\gamma}\right)_{j}^{n+1}$ is instant $\gamma$-spectrum in $\gamma$-energy group with $n+1$ iteration.

The final step to determine whether the iteration process can be quit involves resolution of the following assumption:

$$
\begin{gathered}
\max \left[1-q_{\gamma}\left(r_{p}, E_{\gamma}\right)_{i} / q_{\gamma}\left(r_{p}, E_{\gamma}\right)^{n}\right]<\xi_{0} \\
\xi_{0}=\delta \xi \sum_{m=1}^{M} S q^{2}\left[q_{\gamma}\left(r_{p}, E_{\gamma}\right)\right]_{m}^{-1}
\end{gathered}
$$

where $\xi_{0}$ is assigned accuracy; $\delta \xi$ is the factor determined from test of $\gamma$-spectrum reduction; $S q$ is relative dispersion of power shift in the cylinder body.

Consequently with insertion of in-core sensors fabricated from materials with various atomic numbers and absorption factors having insignificant contribution to elastic and inelastic

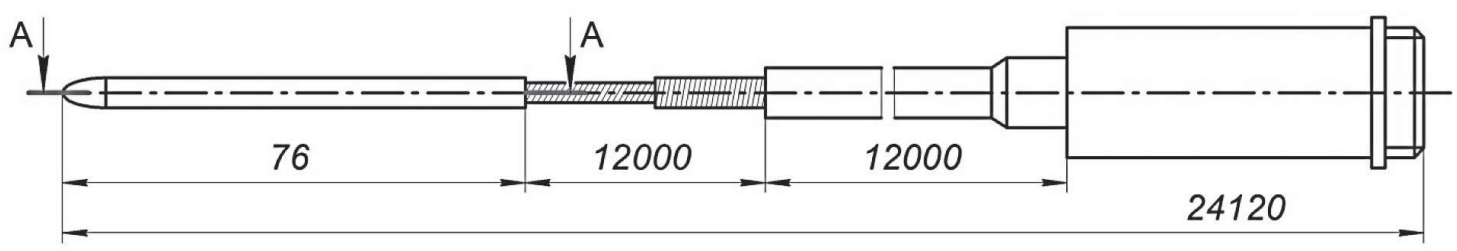

Fig. 5. Calorimetric $\gamma$-sensor 


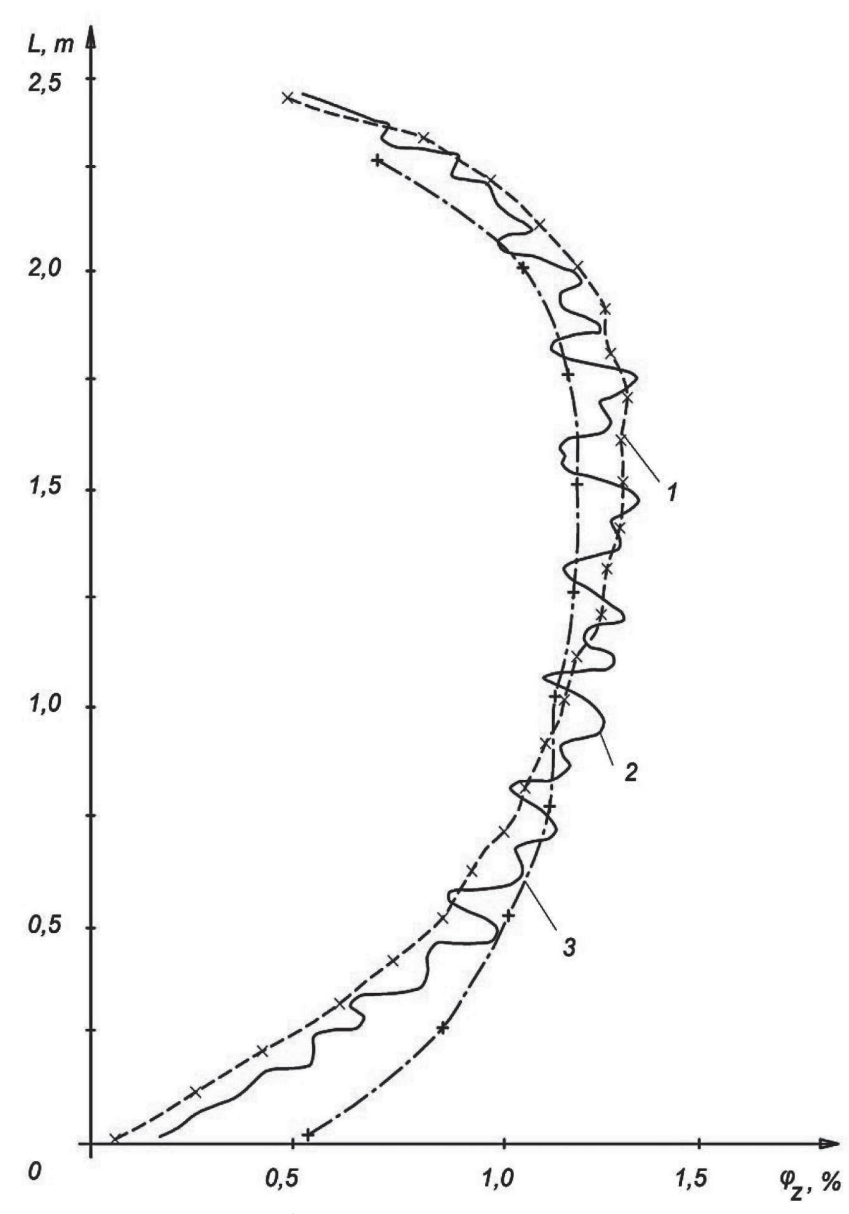

Fig. 6. Relative power distribution

fast neutron scattering and radiation capture (e.g., $\mathrm{Bi}, \mathrm{Pb}, \mathrm{Zr}$, $\mathrm{Fe}, \mathrm{W})$ and dose rate, in-core energy release may be determined with a reliable accuracy $( \pm 20 \%)$ for practical purposes.

For energy release monitoring, $\gamma$-calorimeter has been designed with sensitive and grade scale elements [30]. The calorimetric $\gamma$-sensor (see Fig. 5) was subjected to full-scale performance testing in operating nuclear reactors. Experiments carried out with the gamma calorimeter proved that primary $\gamma$-radiation contribution for WWER accounted to $80 \%$ and secondary one to $20 \%$.

The instant $\gamma$-radiation accounted to almost $70 \%$ and delayed one to $30 \%$. Fig. 6 presents relative axial power distribution $\left(\varphi_{z}\right)$ measured by the gamma-calorimeter (1) and activation detector (2) and profile BIPR-5 calculated for WWER-440.

The tests with control rod insertion showed that $2 / 3$ of primary $\gamma$-radiation was absorbed in the fuel assembly where GC was located, and the share of $\gamma$-radiation from the surrounding fuel elements exceeded $15 \%$ in the total dose rate, being in agreement with the above assumptions.

\section{Conclusions}

The production of energy at nuclear power plants is closely related to the reliability and efficiency of plant operation, engineering characteristics, in-core geometry and energy stress increase. Therefore, considerable elaboration of methods and means for in-core reactor monitoring has been observed, following sophisticated ICIS functions (diagnosis, identification, detection of anticipated operational occurrences). Hence, the most important issues facing new types of ICIS design that need to be investigated further are as follows:

- further research of nonconventional monitoring and instrumentation methods;

- selection of reliable in-core instrumentation, excluding burnup of sensitive elements, with self-calibration of in-core detectors;

- optimization of the most informative fluxes and features in anticipated operational occurrences in the early stage of their development;

- development of effective procedure for treatment and analysis of measurement data and recognition of accident conditions;

- development of mathematical basis and software for implementation of the above procedure;

- determination of the design and architecture of information management system, detector sets, cable trains, plant-specific software;

- further investigation of human-machine interface.

\section{References}

1. Azarov S. I. Probabilistic trends in development of methods and systems for monitoring of current reactor core condition // Atomnaya tekhnika za rubezhom. - 1988. - Vol. 2. - P. 8-13. (Rus).

2. Haebler D. Aeroball system for PWR Instrumentation for Nuclear Power Plant Control (Rep. Panel, Vienna, 1969), Rep. IA2A-119. Vienna, 1970. - P. 70-88

3. Hilborn $J$. W. Self-powered neutron detectors. Summary of a paper // Trans. Amer. Nucl. Soc. - 1963. - Vol. 6. - P. 33, 34.

4. Loving G. $O$. Neutron, temperature and gamma sensors for pressurized water reactors // IEEE Trans. Int. Electron and Contr. Instrum. - 1970. - Vol. 17. - No. 2. - P. 120-124.

5. Cervelati R., Gislou R., Bispoli B. A study on some models of neutron thermopiles // Nucl. Instr. and Meth. - 1966. - Vol. 45. P. 221-232.

6. Stutheit J. S. Fast response gamma thermometers // Nucl. Instr. and Meth. - 1968. - Vol. 63, No. 3. - P. 300-306.

7. Heremann R., Warrinknhoff $H$. Self-powered dosimeter for gamma and X-radiation // Nucleonics. - 1964. - Vol. 22. - No. 3. P. 51, 52 .

8. Bock $H$. Miniature detectors for reactor in-core neutron flux monitoring // Atomic Energy Review. - 1976. - Vol. 14, No. 1. P. 87-132.

9. Wear J. I. Neutron flux instrumentation for a boiling water reactor // Syst. Technol. - 1976. - No. 25. - P. 6-13.

10. Bragan B. A. In-core reactor instrumentation systems for WWER nuclear power plants. - Moscow : Energoatomizdat, 1987. P. 128. (Rus)

11. Emelyanov I. X. et al. System of monitoring the distribution of energy release in an RBMK reactor // Nucl. Power Plant Contr. and Inst. Int. Symp., 1978, Prague, 22-26 January. - Vienna : IAEA, 1978. - P. 683-690 (Rus).

12. Goldsten N. P., Todt W. H. A survey of self-powered detectors present and future // IEEE Trans. Fuel. Sci. - 1979. - Vol. 26, No. 1. - P. 916-923.

13. Hellstrand E., Svanssan L. Advanced hardware and software systems for reactor power monitoring. Oper. Safety Nucl. Power Plants. Int. Symp., 1983, Marseilles, 2-6 May, IAEA, Vienna. - Vol. 1. P. $301-311$.

14. Kroon I. Initial absolute calibration factors of some neutron sensitive self-powered detectors. IAEA specialist meeting, Ontario, Canada, 1974, AECL-5124-110. - P. 135-150.

15. Adamo E. G. Automation information RBMK-1500 control system. State and perspectives. Man-machine interface in the nuclear 
industry. Conf. Proc., Tokyo, 15-19 February 1988, IAEA, Vienna. P. $97-106$.

16. Warren H. D. Performance of pairs of hafnium and rhodium self-powered in-core detectors in a pressurised water reactor // Nucl. Sci. and Eng. - 1984. - Vol. 88. - P. 486-494.

17. Kendoush A. A. Performance of platinum self-powered neutron detectors in the emulated conditions of a pressurised water reactor // Atomkernenerg. Kertechn. - 1983. - Vol. 42, No. 3. - P. 174-176.

18. Allan C. G. Response characteristics of self-powered flux detectors in CANDU reactors // Nucl. Power Plant Contr. and Instr., Int. Symp., 1978, Cannes, 24-28 April, IAEA, Vienna. - Vol. 2. P. 325-337.

19. Allan C. G. Resent advances in self-powered flux detector development for CANDU reactors // Nucl. Power Plant Contr. and Instr., Int. Symp., 1983, Munich, 11-15 October, IAEA, Vienna. P. 505-520.

20. Leyse H. H., Smith B. D. Gamma thermometer development for light water reactors // 25th Nucl. Sci. Symp. Syst, 1978, Washington, 18-20 October, IEEE Trans. Nucl. Sci., 1979. - Vol. 26, No. 1. P. 934-943.

21. Waring I. P., Smith R. D. Recent reactor testing and experience with gamma thermometers // IEEE Trans. Nucl. Sci. - 1983. Vol. 30, No. 1. - P. 791-794.

22. Houtouche $C$. Comparative study of measurements by means of gamma thermometer strings with fission chamber measurements // Nucl. Technol. - 1984. - Vol. 65, No. 3. - P. 462-466.

23. Azarov S. I. Calorimetric sonde for the energy release monitoring channels in the atomic power station vessel reactors. Kiev : Preprint KINR-82-20, 1982. - P. 12.
24. Azarov $S$. I. Retrospective analyses of in-reactor control system evolution. Dynamics and control in nuclear power stations. 2224 October 1991. Inst. of Civil Eng., London. - P. 63-70.

25. Azarov S. I., Tomchay S. P., Tokarevskiy V. V. Use of calorimetric detectors for nuclear installations // Atomnaya tekhnika za rubezhom. - 1992. - Vol. 11. - P. 1-8 (Rus).

26. Azarov $S$. I. In-core detectors and control systems for power reactors. - Kiev : Preprint KINR-93-94, 1993. - P. 24.

27. Tokarevskiy V. V., Azarov S. I. Detectors in instrument construction for reactor equipment. - Kiev : Preprint KINR-87-20, 1987. - P. 46.

28. Azarov S. I. Patent 1677019. Calorimetric Detector. MKIG01T1/12/, 1991. - P. 4.

29. Azarov S. I. Patent 1820760. Method of In-core Control for Nuclear Installation. MKIG21C 17/00/, 1992. - P. 7.

30. Azarov S. I. Patent 1829702. Method of In-Reactor Control System in the Atomic Power Station. MKIG21C 17/00/, 1992. - P. 5.

Отримано 07.07.2014. 